\title{
МАСС-СПЕКТРЫ МОНОЗАМЕЩЕННЫХ ЦИКЛОПЕНТЕНОВЫХ УГЛЕВОДОРОДОВ
}

\section{2. Изоалкилциклопентены}

В настоящей работе изучены масс-спектры 1- и 3-изопропил-, -изобутил- и -изопентил-1-циклопентенов с целью выявления влияния структуры и положения заместителя на диссоциативную ионизацию под действием электронного удара. Спектры снимались на масс-спектрометре MX-1303 при температуре ионного источника и системы напуска $200^{\circ} \mathrm{C}$ и при энергиях ионизирующих электронов $10,12,14,16,18,20,22,25$, 35 и 50 эв. Методика работы описана ранее [1,2]. Относительные интенсивности основных осколочных ионов приведены в табл. $1,2$.

Из масс-спектров 1- и 3-изопропил-, -изобутил- и -изопентил-1-циклопентенов (табл. 1, 2) вытекает, что основные закономерности распада, установленные для $\boldsymbol{H}$-алкилциклопентенов $\left[{ }^{1,2,3}\right]$, действительны и для изоалкилциклопентенов. Кроме того, алкильные заместители с изостроением дают осколки с разрывом связей на месте разветвления. При 50 эв различия между изо- и $H$-алкилциклопентенами в устойчивости молекулярных ионов малы, но становятся более заметными при уменьшении энергии ионизирующих электронов. Значения $W_{M}$ уменьшаются как с возрастанием числа углеродных атомов в заместителе $\mathrm{C}_{3}-\mathrm{C}_{5}$, так и с увеличением энергии бомбардирующих электронов (табл. 1, 2).

При низких энергиях электронов стабильность молекулярных ионов у 1- и 3-изобутил- и -изопентил-1-циклопентенов меньше, а у 1-и 3-изопропил-1-циклопентенов больше, чем у соответствующих соединений с неразветвленной цепью заместителя. Стабильность молекулярных ионов у 1-изомеров значительно больше, чем у 3-замещенных изоалкилциклопентенов, причем эти различия наибольшие при низких энергиях электронов. Например, при 20 эв значения $W_{M}$ у 1 - и 3 -изопропил- и -изобутил-1-циклопентенов отличаются в 1,7 раза, у 1- и 3-изопентил-1-циклопентенов в 2,7 раза, а при 50 эв - в 1,45, 1,6 и 2,4 раза соответственно.

При распаде изопропилциклопентенов с большой вероятностью протекает процесс отщепления метильного радикала, который обусловлен преимущественным расщеплением C-C-связи у места разветвления углеродной цепи заместителя, при этом образуются ионы $\left(\mathrm{C}_{7} \mathrm{H}_{11}\right)+\mathrm{c} \mathrm{m} / \mathrm{e} 95$. Образование этих ионов из 1-изопропил-1-циклопентенов связано с разрывом $\beta$-C-C-связи по отношению к двойной. Этот процесс является также главным процессом распада наряду с $\alpha$-разрывом (к циклу). 


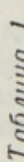

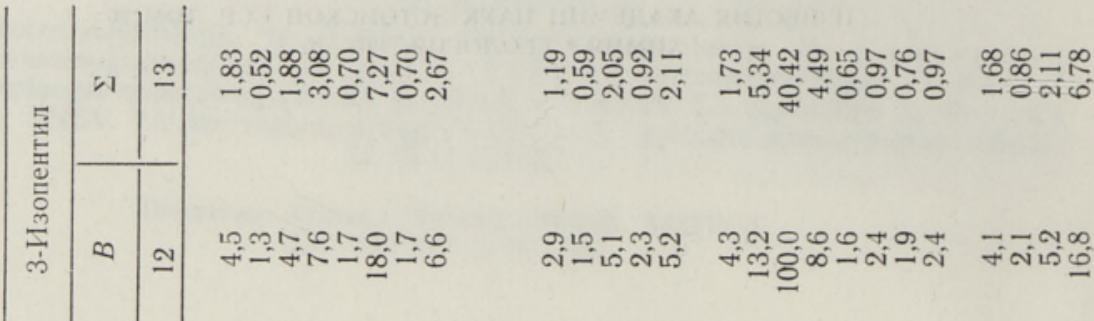



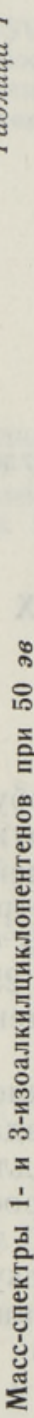





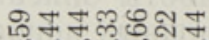
óci-nint

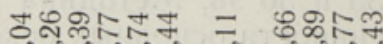

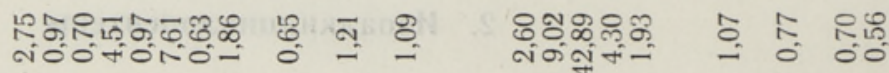

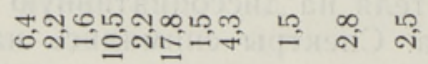

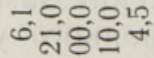

$\stackrel{10}{\sim} \stackrel{0}{=}$

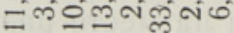

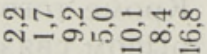

$0, \infty N \infty N$

migon-

ๆ

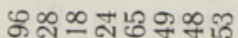

त० ल0

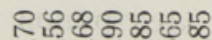

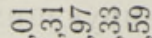

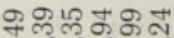

5040

ब

óno-0-

กส่ก

$-0+-00$

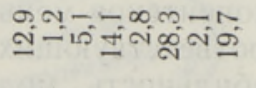

लंज्ञ

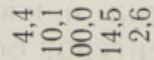

$\log 20000$

$\infty+$

man

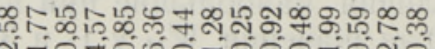

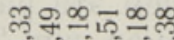

a.

윢ํํํำ

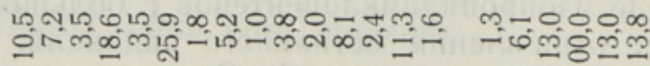

ONNOM-

$\infty$ N

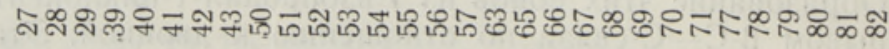




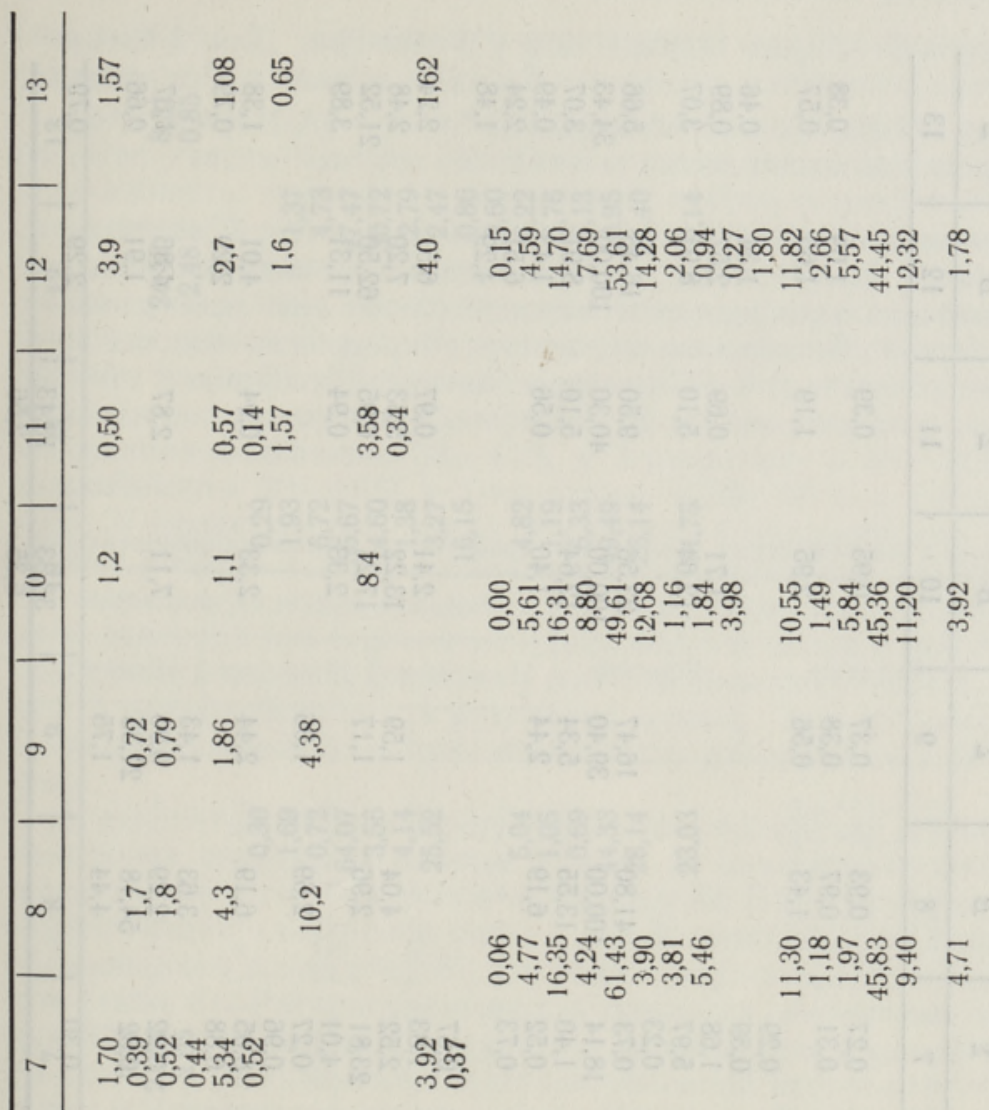

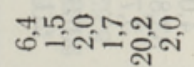
$\stackrel{\infty}{ \pm}$

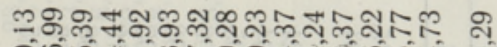
- O以

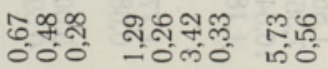

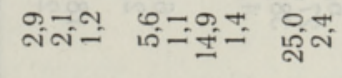

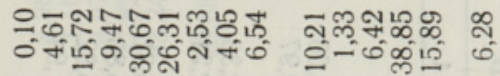

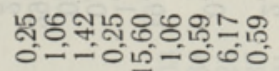
สิกิำดีนกำก

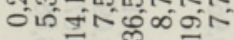

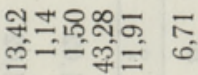

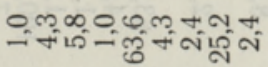

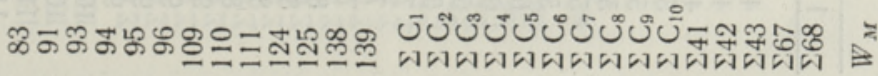




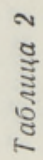

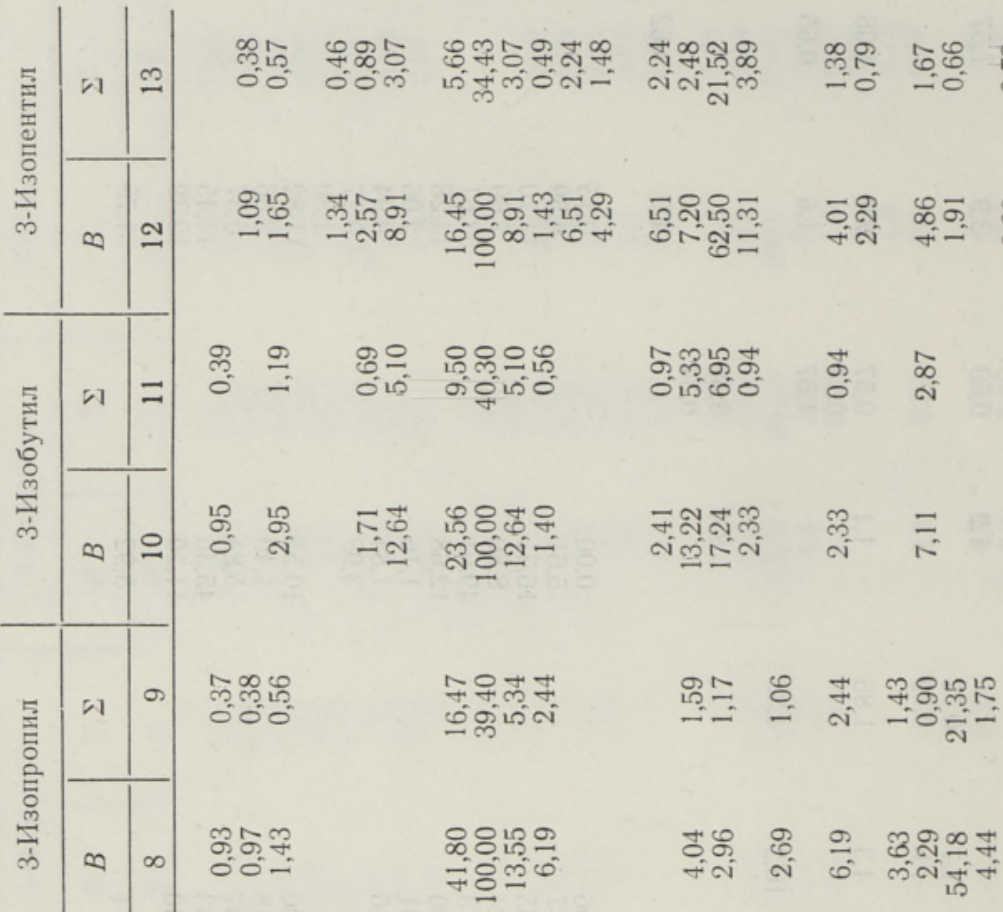

$\operatorname{ses}$

ขึ? กำ

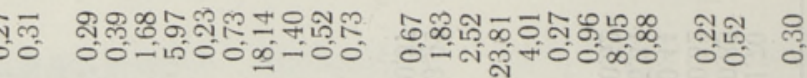

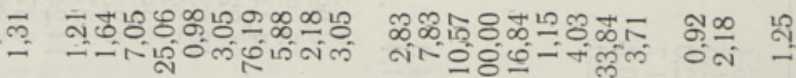

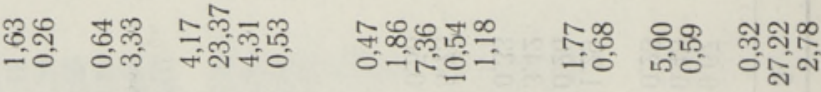

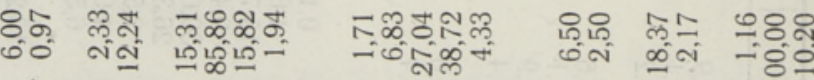

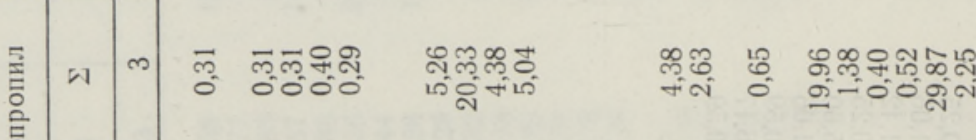

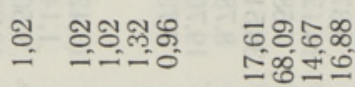

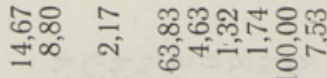


$\vec{m} \infty$

Nָ

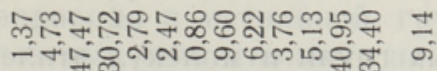

ते

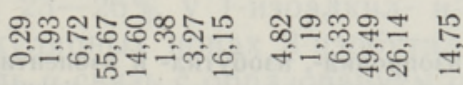

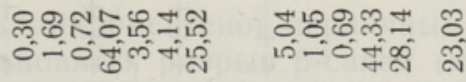

ลูกัด

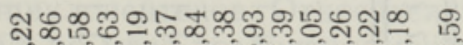
00 సี

-

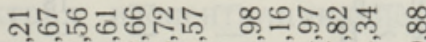

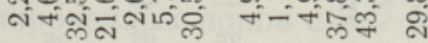

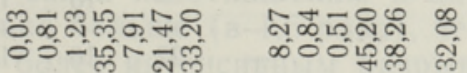

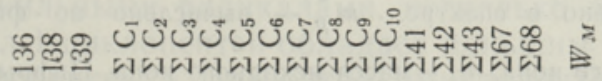


$I_{95}$ у 1-изомера в $8-12$ раз больше, чем у 3-изомера. Для 3-изопропил-1-циклопентена первичным процессом распада является образование осколочных ионов $\left(\mathrm{C}_{5} \mathrm{H}_{6}\right) \pm$ с $m / e 66$ и $\left(\mathrm{C}_{5} \mathrm{H}_{7}\right)+\mathrm{c} m / e 67$. Наряду с этим наблюдаются процессы отщепления метильной группы и двух атомов водорода.

Реакции отщепления этильных групп и молекул этилена, ведущие к образованию ионов с $m / e 81$ и 82 , при распаде изопропилциклопентена протекают со значительно меньшей вероятностью, чем при распаде $\mu$-пропилциклопентена. Возникновение перегруппировочных ионов с $\mathrm{m} / \mathrm{e}$ 82 связано кроме разрыва $\beta$-С-С-связи (к циклу) с миграцией атомов водорода от $\gamma$-углеродного атома. В молекуле 1-изопропил-1-циклопен-

Таблица 3

Метастабильные ионы в масс-спектрах изопропил-, изобутил- и изопентилциклопентенов

\begin{tabular}{|c|c|c|c|c|c|c|c|c|c|}
\hline \multirow{3}{*}{$m^{*}$} & \multirow{3}{*}{$m_{p}^{*}$} & \multirow{3}{*}{ Переход } & \multirow{3}{*}{ Реакция } & \multicolumn{6}{|c|}{ Боковая цепь и ее положение } \\
\hline & & & & \multicolumn{2}{|c|}{ Изопропил } & \multicolumn{2}{|c|}{ Изобутил } & \multicolumn{2}{|c|}{ Изопентил } \\
\hline & & & & 1 & 3 & 1 & 3 & 1 & 3 \\
\hline
\end{tabular}

\begin{tabular}{|c|c|c|c|c|c|c|c|c|c|}
\hline$A$ & $\begin{array}{l}25,1 \\
37,1 \\
63,1 \\
64,1 \\
65,1 \\
77,1 \\
89,0 \\
91,1\end{array}$ & $\begin{array}{l}25,14 \\
37,10 \\
63,06 \\
64,06 \\
75,05 \\
77,05 \\
89,04 \\
91,04\end{array}$ & $\begin{array}{l}29^{+}=27^{+}+2 \\
41^{+}=39^{+}+2 \\
67^{+}=65^{+}+2 \\
68^{+}=66^{+}+2 \\
79^{+}=77^{++} \\
81^{+}=79^{+}+2 \\
93^{+}=91^{++2} \\
95^{+}=93^{++}\end{array}$ & & $\begin{array}{l}+ \\
+ \\
+ \\
+ \\
+ \\
+ \\
+ \\
+\end{array}$ & $\begin{array}{l}+ \\
+ \\
+ \\
+ \\
+ \\
+ \\
+\end{array}$ & $\begin{array}{l}+ \\
+ \\
+ \\
+ \\
+ \\
+ \\
+\end{array}$ & $\begin{array}{l}+ \\
+ \\
+ \\
+ \\
+ \\
+ \\
-\end{array}$ & $\begin{array}{l}+ \\
+ \\
+ \\
- \\
+ \\
+ \\
+ \\
+\end{array}$ \\
\hline E & $\begin{array}{l}40,8 \\
47,3 \\
48,2 \\
48,6 \\
48,7 \\
54,2 \\
54,7 \\
55,7 \\
56,4 \\
57,4 \\
59,7 \\
60,2 \\
72,3 \\
74,3\end{array}$ & $\begin{array}{l}40,81 \\
47,25 \\
48,17 \\
48,67 \\
48,72 \\
54,23 \\
54,74 \\
55,71 \\
56,39 \\
57,36 \\
59,65 \\
60,19 \\
72,78 \\
74,32\end{array}$ & $\begin{array}{r}110^{+}=67^{+}+43 \\
95^{+}=67^{+}+28 \\
96^{+}=68^{+}+28 \\
95^{+}=68^{++}+27 \\
138^{+}=82^{+}+56 \\
124^{+}=82^{++}+42 \\
82^{+}=67^{+}+15 \\
83^{+}=68^{+}+15 \\
82^{+}=68^{++}+14 \\
83^{+}=69^{+}+14 \\
110^{+}=81^{+}+29 \\
109^{+}=81^{+}+28 \\
124^{+}=95^{+}+29 \\
124^{+}=96^{+}+28\end{array}$ & $\begin{array}{l}\alpha-\mathrm{p} \\
\alpha-\mathrm{p} \\
\alpha \sim \mathrm{H} \\
\alpha \sim \mathrm{H} \\
\beta \sim \mathrm{H} \\
\beta \sim \mathrm{H} \\
\alpha-\mathrm{p} \\
\alpha \sim \mathrm{H} \\
\alpha \sim \mathrm{H} \\
\alpha \sim 2 \mathrm{H} \\
\beta-\mathrm{p} \\
\beta-\mathrm{p} \\
\gamma-\mathrm{p} \\
\gamma \sim \mathrm{H}\end{array}$ & $\begin{array}{l}\overline{14} \\
\overline{-} \\
\overline{-} \\
\overline{14} \\
\overline{-} \\
\overline{12} \\
- \\
-\end{array}$ & $\begin{array}{l}\overline{18} \\
- \\
- \\
\overline{-} \\
\overline{-} \\
\overline{14} \\
\overline{-}\end{array}$ & $\begin{array}{l}\overline{20} \\
\overline{-} \\
\overline{-} \\
\overline{12} \\
\overline{-} \\
\overline{-} \\
\overline{25} \\
18 \\
-\end{array}$ & $\begin{array}{l}\overline{20} \\
\overline{-} \\
\overline{1} \\
12 \\
\overline{12} \\
\overline{50} \\
\overline{-} \\
\overline{-}\end{array}$ & $\begin{array}{l}22 \\
14 \\
12 \\
- \\
- \\
12 \\
16 \\
16 \\
50 \\
50 \\
50 \\
-\end{array}$ \\
\hline$B$ & $\begin{array}{l}15,3 \\
24,4 \\
25,1 \\
29,1 \\
29,6 \\
35,6 \\
36,5 \\
36,5 \\
38,2 \\
39,1 \\
40,7 \\
41,3 \\
42,6\end{array}$ & $\begin{array}{l}15,29 \\
24,36 \\
25,09 \\
29,09 \\
29,63 \\
35,56 \\
36,45 \\
36,45 \\
38,24 \\
39,14 \\
40,71 \\
41,30 \\
42,56\end{array}$ & $\begin{array}{l}55^{+}=29^{+}+26 \\
69^{+}=41^{+}+28 \\
67^{+}=41^{+}+26 \\
55^{+}=40^{+}+15 \\
54^{+}=40^{+}+14 \\
82^{+}=54^{+}+28 \\
80^{+}=54^{+}+26 \\
83^{+}=55^{+}+28 \\
82^{+}=56^{+}+26 \\
83^{+}=57^{+}+26 \\
69^{+}=53^{+}+16 \\
68^{+}=53^{+}+15 \\
66^{+}=53^{+}+13\end{array}$ & & $\begin{array}{l}35 \\
18 \\
16 \\
= \\
= \\
= \\
= \\
- \\
- \\
-\end{array}$ & $\begin{array}{l}25 \\
22 \\
20 \\
- \\
- \\
\overline{-} \\
\overline{-} \\
\overline{-} \\
\overline{-}\end{array}$ & $\begin{array}{l}35 \\
20 \\
16 \\
- \\
\overline{16} \\
\frac{16}{16} \\
\frac{16}{-}\end{array}$ & $\begin{array}{l}20 \\
20 \\
20 \\
20 \\
12 \\
14 \\
16 \\
\frac{16}{16} \\
\end{array}$ & $\begin{array}{l}35 \\
35 \\
25 \\
20 \\
- \\
\overline{18} \\
18 \\
22 \\
\\
-\end{array}$ \\
\hline
\end{tabular}

Примечание. $m^{*}$ - обнаружено в спектре. $m_{p}^{*}$ - вычислено по формуле $m^{*}=\frac{m_{2}^{2}}{m_{1}}$, где $m_{2}-$ масса образованного иона, $m_{1}$-масса исходного иона. Цифры пока. зывают величину минимальной энергии электронов, при которой еще регистрировались линии соответствующих метастабильных ионов. 
тена водород в $\gamma$-положении отсутствует, с чем и связана малая интенсивность пиков ионов $\left(\mathrm{C}_{6} \mathrm{H}_{10}\right) \stackrel{+}{\text {. }}$

Для 1-изобутил-1-циклопентена первичным процессом распада является разрыв $\beta$-связи (кциклу и двойной связи) с миграцией водорода $(\beta \sim \mathrm{H})$. Подвижность водорода в метильной группе в изобутиловом радикале ограничена [ $\left.{ }^{4}\right]$, поэтому интенсивность ионов с m/e 82 меньше, чем в случае неразветвленной боковой цепи (примерно в 1,5 раза). При повышении энергии ионы с $m / e 82$ подвергаются распаду с преобладающим образованием ионов с $\mathrm{m} / \mathrm{e} 67$, что подтверждается метастабильными переходами (табл. 3). Количество ионов $\left(\mathrm{C}_{5} \mathrm{H}_{7}\right)+\mathrm{c} m / e 67$ в масс-спектрах у изоалкилциклопентенов $\mathrm{C}_{8}-\mathrm{C}_{10}$ при 50 эв меньше, чем у соответствующих $H$-алкилциклопентенов: $38-43 \%$ у 3 -изоалкил- и $46-51 \%$ у 3 -н-алкилциклопентена, $23-26 \%$ у 1-изоалкил- и $28-36 \%$ у 1-н-алкилциклопентена. В молекулярных ионах 3-изобутил-1-циклопентена разрывается в первую очередь $\alpha$-связь с образованием осколочных ионов с $m / e 67$ и 66 . Наряду с $\alpha$-разрывом в меньшей мере происходит $\beta$-разрыв с миграцией водорода и в основном с образованием ионов с $m / e ~ 81$. Относительные интенсивности последних у изобутилциклопентенов в 3 раза больше, чем у циклопентенов с н-бутильной цепью. Это объясняется тем, что $\mathrm{C}-\mathrm{C}$-связь имеет бо́льшую вероятность разрушения у места разветвления.

$\mathrm{y}$ изопентилциклопентенов первичным процессом распада молекулярных ионов становится разрыв $\beta$-связи (к циклу) с миграцией водорода, в результате чего образуются ионы с $m / e 82$. При увеличении энергии бомбардирующих электронов ионы с $m / e 82$ распадаются с преобладающим образованием ионов с $m / e$ 67, что подтверждается метастабильным переходом (табл. 3). Распространенность основных осколочных нонов $\left(\mathrm{C}_{5} \mathrm{H}_{7}\right)+\mathrm{c}$ $m / e 67$, возникающих в результате отщепления боковой цепи от цикла $(\alpha$-разрыв), у циклопентенов с разветвленной цепью заместителя меньше, чем у $н$-алкилциклопентенов. Относительные интенсивности линий ионов c m/e 67 растут по мере увеличения энергии электронов до 20 эв, около которой кривая изменения их интенсивности пройдет через максимум (табл. 1,2 ).

Как у $\boldsymbol{H}$-алкилциклопентенов, так и у соответствующих изоалкильных производных, заместитель отщепляется от кольца с $1,5-2$ раза большей вероятностью у 3 -изомеров, так как разрывается $\beta$-связь по отношению к двойной.

В масс-спектрах изопентилциклопентена относительные интенсивности перегруппировочных ионов с $m / e 82$ больше, чем у $H$-пентилциклопентена. Это объясняется повышенной подвижностью атома водорода у третичного углеродного атома разветвленного заместителя. Интенсивности ионов $\left(\mathrm{C}_{6} \mathrm{H}_{9}\right)+\mathrm{c} m / e 81$ имеют близкие значения, что обусловливается примерно одинаковыми энергиями разрываемых C-C-связей [5]. Относительная интенсивность ионов $\left(\mathrm{C}_{7} \mathrm{H}_{11}\right)+\mathrm{c} m / e 95$, образующихся при разрыве $\gamma$-связи по отношению к циклу, у 1-изопентил-1-циклопентена значительно больше (в 1,5 раза), чем у 1-н-пентил-1-циклопентена, что связано с более интенсивным разрывом C-C-связей около разветвления углеродной цепи.

Кривые распределения интенсивностей по числу углеродных атомов в ионах (рисунок), отвечающие 1-замещенным циклопентенам с $\boldsymbol{H}$ - и изоалкильными радикалами, несколько отличаются - при 50 эв 1-изопропил-1-циклопентен обладает меньшим значением $\Sigma \mathrm{C}_{7}$, чем 1-н-пропил1 -циклопентен, а 1-изобутил-1-циклопентен - бо́льшими $\Sigma \mathrm{C}_{5}$ и $\Sigma \mathrm{C}_{6}$, чем 1-н-бутил-1-циклопентен. В случае пяти углеродных атомов в цепи заместителя кривые распределения в диапазоне энергий электронов 20-50 эв 


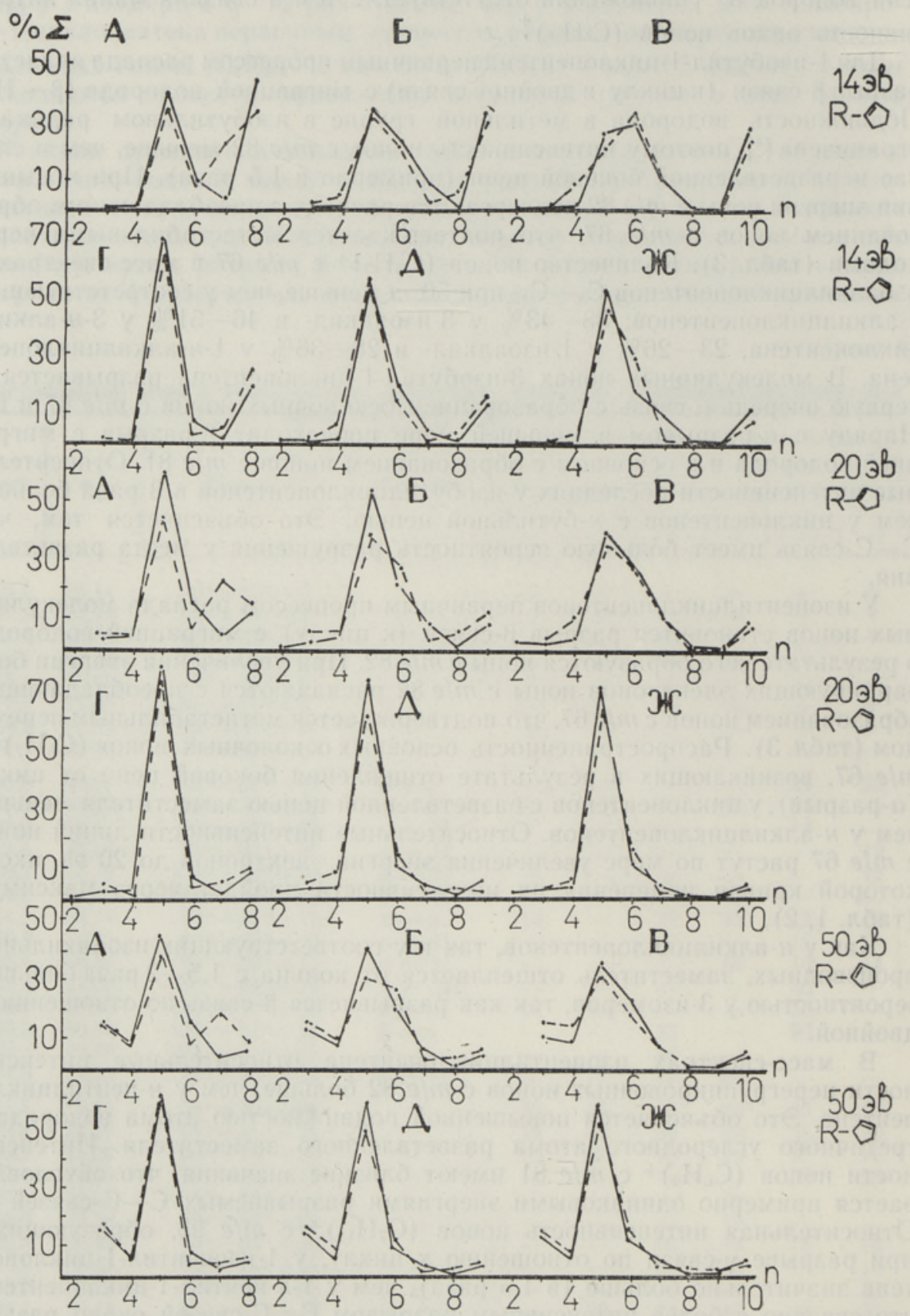

Распределение интенсивностей в масс-спектрах 1- и 3-изоалкилциклопентенов $(---)$ и -н-алкилциклопентенов (- при 14,20 и 50 эв.

$A-1$-изопропил- и -н-пропилциклопентен, $D-1$-изобутил- и -н-бутилциклопентен, $B-1$-изопентил- и - $\boldsymbol{\mu}$-пентилциклопентен, $\Gamma-3$-изопропил- и - $\boldsymbol{\mu}$-пропилциклопентен, Д - 3-изобутил- и -н-бутилциклопентен, Ж - 3-изопентил- и -н-пентилциклопентен. 
Характерные суммы 1- и 3-изопропил-, изобутил-, изопентил-, $\boldsymbol{t}$-пропил-, $\boldsymbol{u}$-бутил- и $\boldsymbol{\mu}$-пентил-1-циклопентенов

\begin{tabular}{|c|c|c|c|c|c|c|c|c|c|}
\hline \multirow{3}{*}{ Соединение } & \multicolumn{9}{|c|}{ Энергия ионизирующих электронов, эв } \\
\hline & \multicolumn{3}{|c|}{$\Sigma 41$} & \multicolumn{3}{|c|}{$\Sigma 67$} & \multicolumn{3}{|c|}{$\Sigma 68$} \\
\hline & 14 & 20 & 50 & 14 & 20 & 50 & 14 & 20 & 50 \\
\hline $\begin{array}{l}\text { 1-н-Пропил-1-циклопентен } \\
\text { 1-Изопропил-1-циклопентен } \\
\text { 3-н-Пропил-1-циклопентен } \\
\text { 3-Изопропил-1-циклопентен } \\
\text { 1-н-Бутил-1-циклопентен } \\
\text { 1-Изобутил-1-циклопентен } \\
\text { 3-н-Бутил-1-циклопентен } \\
\text { 3-Изобутил-1-циклопентен } \\
\text { 1-н-Пентил-1-циклопентен } \\
\text { 1-Изопентил-1-циклопентен } \\
\text { 3-н-Пентил-1-циклопентен } \\
\text { 3-Изопентил-1-циклопентен }\end{array}$ & $\begin{array}{l}4,66 \\
8,27 \\
2,99 \\
5,04 \\
5,39 \\
4,98 \\
4,35 \\
4,82 \\
8,73 \\
7,39 \\
5,76 \\
6,22\end{array}$ & $\begin{array}{r}6,53 \\
11,11 \\
4,94 \\
6,36 \\
5,62 \\
5,04 \\
4,51 \\
4,64 \\
7,92 \\
7,90 \\
4,71 \\
5,31\end{array}$ & $\begin{array}{l}10,90 \\
14,50 \\
10,19 \\
11,30 \\
10,95 \\
10,21 \\
10,60 \\
10,55 \\
13,00 \\
14,24 \\
11,22 \\
11,82\end{array}$ & $\begin{array}{l}39,99 \\
45,241 \\
63,08 \\
44,33 \\
37,55 \\
37,82 \\
46,79 \\
49,49 \\
31,19 \\
29,22 \\
47,74 \\
40,95\end{array}$ & $\begin{array}{l}58,82 \\
55,43 \\
70,34 \\
57,45 \\
56,31 \\
49,46 \\
66,15 \\
56,27 \\
47,65 \\
44,87 \\
64,27 \\
58,53\end{array}$ & $\begin{array}{l}45,05 \\
43,55 \\
54,55 \\
45,83 \\
43,89 \\
38,85 \\
50,55 \\
45,36 \\
39,17 \\
35,77 \\
49,17 \\
44,45\end{array}$ & $\begin{array}{l}46,24 \\
38,26 \\
24,68 \\
28,14 \\
50,79 \\
43,34 \\
38,92 \\
26,14 \\
51,14 \\
48,18 \\
33,57 \\
34,40\end{array}$ & $\begin{array}{l}19,33 \\
21,78 \\
13,79 \\
14,95 \\
26,80 \\
25,76 \\
17,43 \\
17,63 \\
29,44 \\
29,14 \\
16,16 \\
17,46\end{array}$ & $\begin{array}{r}11,51 \\
13,36 \\
8,73 \\
9,40 \\
15,53 \\
15,89 \\
10,98 \\
11,20 \\
16,35 \\
14,73 \\
11,83 \\
12,32\end{array}$ \\
\hline
\end{tabular}

сходны, а при 14 эв значения $\Sigma \mathrm{C}_{6}$ и $\Sigma \mathrm{C}_{7}$ выше у 1-изопентил-1-циклопентенов. У 3 -н-алкил- и 3-изоалкил-1-циклопентенов $\mathrm{C}_{8}-\mathrm{C}_{10}$ кривые распределения сходны. Значения максимумов на этих кривых, соответствующие ионам $\left(\mathrm{C}_{5} \mathrm{H}_{\mathrm{x}}\right)^{+}$, у 3 -изоалкил-1-циклопентена гораздо больше, чем у 1-изомеров.

Основная часть $\Sigma I$ 1- и 3-изоалкил-1-циклопентенов падает на долю осколочных ионов $\left(\mathrm{C}_{n} \mathrm{H}_{2 n-3}\right)^{+}$, образующих характерную сумму $\Sigma 67$ у $45-55 \%$ изопропил-, у $40-55 \%$ изобутил- и у $30-60 \%$ изопентилциклопентена. Значения этих величин меньше, чем у соответствующих $\boldsymbol{H}$-алкилциклопентенов (табл. 4). Значения $\Sigma 41$ и $\Sigma 68$ у 1- и 3 -циклопентенов как при неразветвленном заместителе, так и при разветвленной цепи близки (табл. 4). Удлинение и разветвление боковой цепи ведет к увеличению количества алкильных ионов в масс-спектрах изоалкилциклопентенов.

\section{Выводы}

Основные закономерности распада молекулярных ионов изоалкил- и $H$-алкилциклопентенов сходны. Заместители с изоструктурой обусловливают характеристические для разветвленных цепей реакции распада. $\mathrm{y}$ изопропилциклопентенов основными первичными реакциями распада являются элиминирование метильной группы и разрыв $\alpha$-связи (к циклу) с образованием ионов с $m / e 95$ и 67 соответственно. У изоалкилциклопентенов $\left(n_{S} \geqslant 4\right)$, кроме 3 -изобутил-1-циклопентена, в первую очередь разрывается $\beta$-связь с миграцией водорода. Образовавшиеся при этом ионы c $m / e 82$ при увеличении энергии электронов подвергаются распаду с преобладающим образованием ионов с $m / e$ 67. В случае 3 -изобутил1 -циклопентена разрывается преимущественно $\alpha$-связь ( $\beta$-связь по отношению к циклу) по сравнению с реакцией $\beta \sim \mathrm{H}$.

1-изомеры обладают большей устойчивостью к электронному удару, чем 3-изомеры, причем стабильность молекулярного иона уменьшается с увеличением числа углеродных атомов в заместителе. У соединений с разветвленной боковой цепью стабильность меньше по сравнению с соответствующими $\boldsymbol{H}$-алкилциклопентенами. 
ЛИ ТЕРА Т У Р А

1. Р анг С., Т а л в а р и А., Эй зе и О., Изв. АН ЭССР, Хим. Геол., 23, № 1, 15 (1974)

2. Р а нг С., Т а л в а р и А.,, Эй з ен О., Изв. АН ЭССР, Хим. Геол., 23, № 2, 117 (1974)

3. Т а л в а р и А., Р анг С., Эй зен О., Изв. АН ЭССР, Хим. Геол., (в печати).

4. Поляков а А. А., Х м ельницкий Р. А., Масс-спектрометрия в органической химии. Л., 1972.

5. Поляко в а А. А., Молекулярный масс-спектральный анализ нефтей. М., 1973.

\section{Институт химии}

Академии наук Эстонской ССР
Поступила в редакцию 13/III 1974

A. TALVARI, Silvia RANG, O. EISEN

\section{MONOASENDATUD TSUKLOPENTEENIDE MASSISPEKTRID}

\section{Isoalküültsüklopenteenid}

Uuriti 1- ja 3-isopropüül-, -isobutüül- ja -isopentüül-1-tsüklopenteenide massispektreid (ioniseerivate elektronide energia $10-50 \mathrm{eV}$ ) ning esitatakse nende tõenäoline fragmentatsiooniskeem. Selgus, et kõrvalahela struktuur ja asend mõjustavad dissotsiatiivset ionisatsiooni.

\section{A. TALVARI, Sylvia RANG, O. EISEN}

\section{MASS SPECTRA OF SUBSTITUTED CYCLOPENTENES}

\section{Isoalkylcyclopentenes}

Mass spectra of 1- and 3-isopropyl-, -isobutyl-and -isopentyl-1-cyclopentenes have been studied at $10-50 \mathrm{eV}$; their general fragmentation scheme is given. Both the structure and position of the side chain affect the fragmentation process. 